\title{
Some further tests of the constant-ratio rule
}

\author{
MILTON H. HODGE \\ UNIVERSITY OF GEORGIA
}

Five experiments sought to test the constant-ratio rule (CRR) with single dimensional ensembles composed of 2, 4, or 8 stimulus objects. Each $S$ attempted to identify stimuli which varied in weight or in visual size or brightness. The results demonstrated: (a) The CRR predicts equally well the response proportions of single dimensional visual, kinesthetic, and auditory stimulus ensembles, but less well than those for multidimensional auditory stimuli. (b) Better predictions are obtained with four than with two stimulus objects. (c) The CRR is sensitive to variations in the spacing and range of the stimulus ensembles and to practice on the task. It is concluded that the rule tends to fail whenever stimulus conditions elicit differential amounts of stimulus and response confusion.

The present report describes the results of several experiments designed to evaluate the constant-ratio rule (CRR) with single dimensional visual and kinesthetic stimuli. Clarke (1957) devised the CRR as a means of predicting the patterns of confusion among stimuli and responses in speech identification tasks, but Luce $(1959,1963)$ has shown that the rule can be derived from a more general theory of choice behavior. In its simplest form, the theory states that, given two sets of well defined stimuli and responses, with one S-R set a subset of the other, knowledge of the choice probabilities for one set permits prediction of the probabilities for the other set. These predictions are based on the assumption that the ratio of the choice probabilities asssociated with any set of two stimuli and two responses are independent of all other stimuli and responses which may be members of the E-defined stimulus ensemble and response set (Clarke, 1957; Hodge \& Pollack, 1962; Luce, 1959). This property of the theory, labeled "independence from irrelevant alternatives" by Luce (1959), is the basis of the CRR. The major consequence of the independence assumption is that the predictions of the CRR should not be influenced by the contextual constraints usually engendered by variations in the number of stimuli and responses, stimulus spacing and range, and frequency of stimulus occurrence. This view of choice behavior contrasts sharply with formulations in which concepts such as anchoring, response bias, and adaptation level are fundamental. A more detailed description of the CRR and its implications can be found in Clarke (1957), Hodge and Pollack (1962), and Atkinson, Bower, and Crothers (1965).

A number of tests has shown that the CRR makes satisfactory predictions of the confusion patterns associated with multidimensional objects such as vari- ous speech stimuli (Clarke, 1957; Clarke \& Anderson, 1957; Carterette \& Wyman, 1961; Pollack \& Decker, 1960), words (Egan, 1957), visually presented monosyllables (Anderson, 1959), and multidimensional auditory tones (Hodge \& Pollack, 1962). In an experiment with simple auditory stimuli, e.g., tones varying in frequency or Intensity, Clarke (1959) noted that the rule tended to fail. In Clarke's opinion, ${ }^{2}$ the rule failed because the ordering inherent in single dimensional stimuli produces contextual constraints or biases which, by definition, are incompatible with the CRR. Hodge and Pollack (1962), however, using tones which varied in intensity or duration, obtained results in which the CRR did predict fairly adequately the confusion patterns, but with somewhat less precision than was the case with the multidimensional stimuli. Although it might be argued that Clarke and Hodge and Pollack simply disagree about what constitutes acceptable CRR predictions, Clarke's view that the CRR will not work with single dimensional stimuli represents an important potential limitation of the rule's generality, and therefore deserves further testing.

The major goal of the present experiments was to test the rule with single dimensional stimuli appropriate to sense modalities other than the auditory. In the present case, visual stimuli and lifted weights were used. A second goal was to examine again the finding that CRR predictions are affected by interstimulus spacing and ensemble range (Hodge \& Pollack, 1962, Experiment VII). Finally, the experiments sought to determine whether CRR predictions are sensitive to the amount of practice on the identification task. Clarke and Anderson (1957) have shown that the CRR makes similar predictions for practiced and naive Ss, but it seemed important to test their result with other stimulus objects. To the extent that the CRR is not affected by practice, the rule is broadened because the behavioral changes associated with practice typically represent stimulus and response interactions involving more than just pairs of stimuli and their responses.

\section{Subjects}

\section{LIFTED WEIGHTS EXPERIMENTS}

The Ss were 12 University of Georgia students (eight in Experiment 1 and four in Experiment 2) who were run singly in daily sessions of $1 \mathrm{~h}$ over a period of two weeks, weekends excluded.

\section{Apparatus and Procedure}

The stimulus objects consisted of eight sand-filled medicine bottles, $1-1 / 4 \times 1-1 / 4 \times 4-3 / 8$ in. The weights 
of the bottles ranged, in $8 \mathrm{~g}$ steps, from 150 to $206 \mathrm{~g}$ in Experiment 1. In Experiment 2, the stimuli were spaced $6 \mathrm{~g}$ apart. A turntable was used to present the bottles one at a time. Placed on the periphery of the turntable, any bottle could be positioned directly in front of a blindfolded $S$. This arrangement permitted $S$ to lift a bottle easily and replace it on the turntable.

For convenience, each stimulus object was assigned a numeral from 1 to 8 , with the $150 \mathrm{~g}$ bottle assigned the numeral 1. When attempting to identify a particular stimulus, $S$ responded by giving one of the eight numerals. Each response was recorded by $E$ on a mark-sense card.

On the first day of the experiment, each S was read a set of instructions which described the stimuli and the task. The $S$ was then given two practice trials (sequences) of 96 stimuli in which all eight bottles occurred randomly and equally often. Four additional practice trials were given on the next day. Whenever $S$ gave an incorrect response, he was corrected by $\mathbf{E}$. Following the training trials, each $S$ in Experiment 1 was given 34 sequences of 96 items with stimulus ensembles consisting of 8,4 , or 2 weights. Each $S$ judged four sequences of 8 objects, two sequences each of 8 ensembles of 4 objects, and one sequence each of 14 ensembles of 2 objects. In Experiment 2, in addition to the four sequences of 8 objects, each $S$ was given 6 ensembles of 4 objects and 12 ensembles of 2 objects. When summed over sequences and Ss, each stimulus in each ensemble was presented 384 times in Experiment 1 and 192 times in Experiment 2. The order of occurrence of the different ensemble sizes was random, l.e., any given sequence could contain 8,4 , or 2 stimulus objects. With the presentation of each new ensemble, $S$ lifted the appropriate bottles and was told their identity. Since informative feedback was not supplied during the experimental sequences, it was necessary to reacquaint $S$ with the stimulus objects to minimize response drifting. During any hourly session, four or five sequences were presented.

\section{Results}

The CRR and Luce's choice theory are explicitly
Table 1. Summary of Results of Lifted Weights Experiments

\begin{tabular}{|c|c|c|c|c|}
\hline Matrix size & $\begin{array}{c}\text { Mean Prop. } \\
\text { Correct }\end{array}$ & $\begin{array}{l}\text { Mean } \\
\text { |Diff.| }\end{array}$ & $\begin{array}{c}\% \\
\text { Diffs. } \\
>.10\end{array}$ & $\begin{array}{c}\text { Alg. Mean } \\
\text { Diagonal } \\
\text { Diffs. }\end{array}$ \\
\hline \multicolumn{5}{|c|}{ Experiment $1: 8 \mathrm{~g}$ Steps } \\
\hline $\begin{array}{l}8 \text { by } 8 \\
4 \text { by } 4 \\
\text { Ist half } \\
\text { 2nd half } \\
2 \text { by } 2 \\
\text { Ist half } \\
\text { 2nd half }\end{array}$ & $\begin{array}{l}.389 \\
.617 \\
.676 \\
.558 \\
.868 \\
.956 \\
.780\end{array}$ & $\begin{array}{l}.039 \\
.033 \\
.045 \\
.084 \\
.020 \\
.148\end{array}$ & $\begin{array}{r}6.2 \\
3.1 \\
9.4 \\
21.4 \\
.0 \\
42.9\end{array}$ & $\begin{array}{l}+.017 \\
+.004 \\
+.030 \\
+.044 \\
-.011 \\
+.099\end{array}$ \\
\hline \multicolumn{5}{|c|}{ Experiment 2: $6 \mathrm{~g}$ Steps } \\
\hline $\begin{array}{c}8 \text { by } 8 \\
4 \text { by } 4 \\
\text { lst half } \\
2 \text { nd half } \\
2 \text { by } 2 \\
\text { lst half } \\
2 n d \text { half }\end{array}$ & $\begin{array}{l}.332 \\
.551 \\
. .642 \\
.459 \\
.787 \\
.914 \\
.659\end{array}$ & $\begin{array}{l}.048 \\
.039 \\
.057 \\
.063 \\
.033 \\
.094\end{array}$ & $\begin{array}{r}11.4 \\
4.2 \\
18.7 \\
25.0 \\
8.3 \\
41.7\end{array}$ & $\begin{array}{r}+.004 \\
+.022 \\
-.014 \\
+.003 \\
-.012 \\
+.018\end{array}$ \\
\hline
\end{tabular}

Note: See text for explanation of the various measures.

concerned with the responses of individual $\mathrm{Ss}$, but Clarke (1957) and Clarke and Anderson (1962) have shown that grouped data provide satisfactory tests of the rule. Grouped data were employed in all calculations of the present experiments.

In Fig, 1 the panel on the left compares the obtained and predicted response proportions of the individual entries of all the 4 by 4 matrices in Experiment 1 . The abscissa is the predicted proportions, derived from the 8 by 8 matrix. The ordinate is the obtained proportions, observed in the 4 by 4 tests. The CRR states that the predicted and obtained proportions should fall exactly on the $45^{\circ}$ line (Clarke, 1957). It can be seen that the rule makes reasonably good predictions. The results for the 2 by 2 matrices are given in the right panel of Fig. 1. It is immediately obvious that the predictions are less accurate than those in the 4 by 4 tests. A numerical analysis of the data is presented in Table 1. The first column gives the matrix size. The next column presents the mean of the obtained proportion of the correct responses (entries on negative diagonal) in the various matrices.
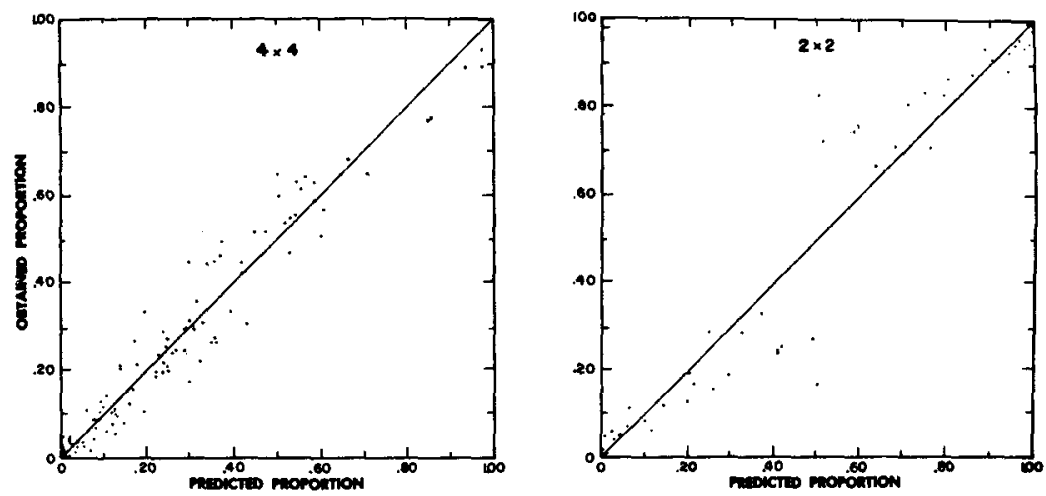

Fig. 1. Predicted and obtained response proportions of the individual 4 by $q$ and 2 by 2 entries of Lifted Weights Experiment 1. 
The third column gives the mean of the differences (sign ignored) between the obtained and predicted proportions for all entries in the 4 by 4 and 2 by 2 matrices. Column 4 shows the percentage of the absolute differences which exceed a difference of .10, a criterion value suggested by Clarke (1957). The last column presents the mean systematic differences (sign not igmored) between the predicted and obtained scores of only the correct responses in the matrices. A positive entry indicates that the obtained score was greater than the predicted score. The rows labeled first half and second half are the result of rank ordering the matrices from high to low in terms of the mean proportion correct and then dividing them into two equal sized groups. The first and second half means are based on the upper and lower groups of the matrices.

Although a satisfactory statistical test is not available (Clarke, 1957), inspection of the difference measures for the 4 by 4 matrices confirms the accuracy of the predictions shown in Fig. 1; all the measures are reasonably small. The analysis also confirms the apparent concentration of the points below the $45^{\circ}$ line, the mean of the algebraic differences is $t_{0} 017$. This systematic clustering indicates that the CRR slightly underestimated the predicted proportions. The less accurate prediction of the 2 by 2 proportions is reflected by the relatively large values of the difference measures for these matrices. Of particular interest is the finding that the grand mean of the systematic differences is approximately two and one-half times larger than the mean of the 4 by 4 matrices ( +.044 vs +.017 ). An examination of the individual 2 by 2 matrices showed that the largest systematic differences are associated with stimulus pairs consisting of adjacent objects, e.g., Stimuli 7,$8 ; 5,6 ; 1,2$.

A comparison of the difference measures for the first and second half 4 by 4 and 2 by 2 matrices shows that the CRR predictions become less accurate with decreases in the mean proportion of correct responses. It is noted that the second half matrices contained many adjacent or nearly adjacent stimuli and responses. The effect of interstimulus spacing is shown more clearly in Fig. 2. The abscissa is the spacing between members of selected stimulus pairs. The ordinate is the mean proportion of incorrect responses (confusability score) for all pairs with the same spacing. The 2 by 2 curve is based on the observed confusability of the pairs while the 8 by 8 and 4 by 4 curves are the confusability scores derived by means of the CRR from appropriate 8 by 8 and 4 by 4 matrices. The main point of the figure is that the derived scores are higher than the observed scores only when the stimulus objects (and their responses) are adjacent or nearly adjacent. A similar result was obtained with auditory stimuli by Hodge and Pollack (1962).

The results of Experiment 2 are also presented in Table 1. It can be seen that the difference measures are similar to those of Experiment 1 with certain exceptions. The major discrepancy is that the mean systematic difference of the second half of the 2 by 2 matrices is considerably smaller in Experiment 2.

\section{VISUAL EXPERIMENTS EXPERIMENT 1: VISUAL AREA}

\section{Subjects}

The Ss were 40 students at the University of Georgia or seniors at the local high school. They were required to work $2 \mathrm{~h}$ a day over a period of six consecutive days, and participated in groups of four, five, or six.

\section{Stimulus Material}

The stimulus objects consisted of four series of eight circles which varied in area. The interstimulus spacing was constant for the objects in a given stimulus series but varied among series. Table 2 illustrates the relations among the stimulus objects of the four series. The spacing (area increments, in in. ${ }^{2}$ ) in the four series was: 1.55 (Series A), 3,10 (Series B), 4.65 (Series C), and 6.20 (Series D). The total area of Stimulus 1 in all series was 50.24 sq. in. As Table 2 indicates, the range of Series B, C, and D was two, three, and four times the range of Series A. As a consequence, certain pairs of circles occur in two or more series (indicated by dotted lines in Table 2). For example, the first pair of stimuli in Series D (numbered from the top and designated D 1-2) is the same pair of circles as B 1-3 and A 1-5. Table 2 also shows that the number of intermediate stimuli between a given pair of circles increases with a reduction in ensemble range. Thus, there are no intermediate stimuli between D 1-2, one between B 1-3, and three between A 1-5. Each stimulus appeared as a gray circle centered on a white background. The projected circles were approximately $60 \%$ larger than the forms which were photographed.

\section{Apparafus}

The experiment was conducted in a small room which was lighted by a $300 \mathrm{~W}$ ceiling lamp. The illumination of the lamp minimized the contrast between the room lighting and that provided by the projector during a stimulus presentation.

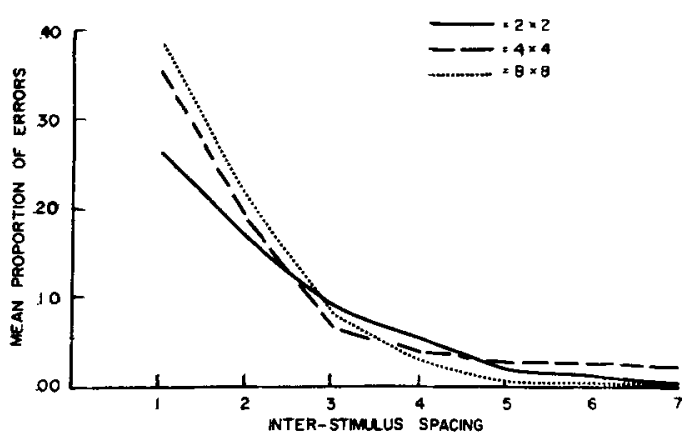

Fig. 2. Confusability scores as a function of interstimulus spacing in Lifted Weights Experiment 1. 
A timer was used to program the projector and an electromagnetic shutter. The $6 \mathrm{sec}$ cycle of the timer was divided among the following events: First, the projector advanced a slide to the projection position. After a $1.5 \mathrm{sec}$ delay, the shutter opened and exposed the stimulus object for $0.5 \mathrm{sec}$. This was followed by a 4 sec blank period during which ss responded. At the end of the response period, the cycle of events was repeated. During each response period, Ss filled in an appropriate space on a mark-sense card.

\section{Design and Procedure}

Four groups of Ss were assigned to one of the four conditions of interstimulus spacing and ensemble range (Series A, B, C, D). The number of Ss assigned to each group was 11 (Series A), 10 each (Series B and C), and 9 (Series D). The inequality of the groups is the result of the unavallability of $S s$ at certain hours. Two groups of Ss were run for each series because of the smallness of the experimental room. On the first day of the experiment, Ss were read a set of instructions which described the stimuli, the task, and the response cards. The instructions read in part: "Your task will be to judge the area of several circular forms projected on the screen at the front of the room. The stimulus objects you are to judge

Table 2 .

Schematic Ilustration of the Stimulus Spacing in Experiment 1

Relative Stimulus Spacing

\section{(1.55 sq. in. units)}

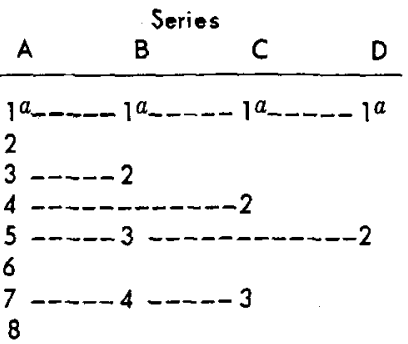

8

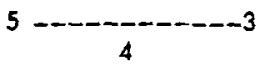

6

12

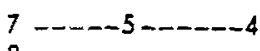

6

16

Note: The numbers represent the stimuli employed in each series.

The dotted lines identify stimuli common to two or more series.

${ }^{a}$ Stimulus $1=50.24 \mathrm{sq}$. in. are elght circles which differ from each other in their total area. For ease of communication, the circles have been labeled with the numerals 1-8. Here are the eight circles in order, starting with Circle 1." The stimuli were projected manually, E identifying each by number. After further explanation, the eight circles were shown again in the same manner. Then a random sequence of 24 items was projected and Ss were asked to identify them verbally, 1.e., give the numeral of the stimulus. Each of the eight circles occurred equally often in this and other sequences. Two additional sequences of 24 circles were then projected automatically. The purpose of these sequences was to test Ss' knowledge of the stimulus objects, familiarize Ss with the pacing procedure, and give $\mathrm{Ss}$ practice in marking the response cards. The correct response for each stimulus was announced at the end of the response period, during the $1.5 \mathrm{sec}$ period between the advancement of the next slide and the opening of the shutter. The Ss were asked not to change their responses. No violation of this request was observed.

Upon completion of the preliminary training, Ss in each group were given 16 practice trials with the eight stimulus objects appropriate to their condition. A trial consisted of a sequence of 96 items, with a brief pause after every 24 to permit changes of response cards. Knowledge of results was supplied for each stimulus. The sequences were presented at the rate of $4 / h$, thus requiring two days to complete 16 trials. There was a brief rest period after the first hour of each dally session.

The experimental trials followed immediately the practice phase, and Ss were told that they would be presented with 32 sequences of 96 items. The $32 \mathrm{se}-$ quences consisted of four sequences of 8 objects, two sequences each of 7 ensembles of 4 objects, and one sequence each of 14 ensembles of 2 objects. When summed over sequences and $\mathrm{Ss}$, each stimulus in each ensemble was presented 528 times in Series A, 480 in Series B and C, and 432 in Series D. All other procedures were similar to those in the lifted weights experiments. Four days were required to collect the experimental data.

\section{Resulis}

The results are arranged to provide answers about: (a) the adequacy of CRR predictions; (b) the effect of spacing and range conditions on the CRR; and (c) the sensitivity of the CRR to practice effects.

CRR Predictions. Flgure 3 shows the predicted and obtained proportions of the individual entries of all the 4 by 4 and 2 by 2 matrices employed in Sertes A. As was the case in the lifted weights experiments (Fig. 1), the CRR makes reasonably good predictions for the 4 by 4 matrices but somewhat poorer predictions for the 2 by 2 data. A numerical evaluation 3 of the 4 by 4 data showed that the mean absolute difference between the obtained and predicted proportions ranges from 

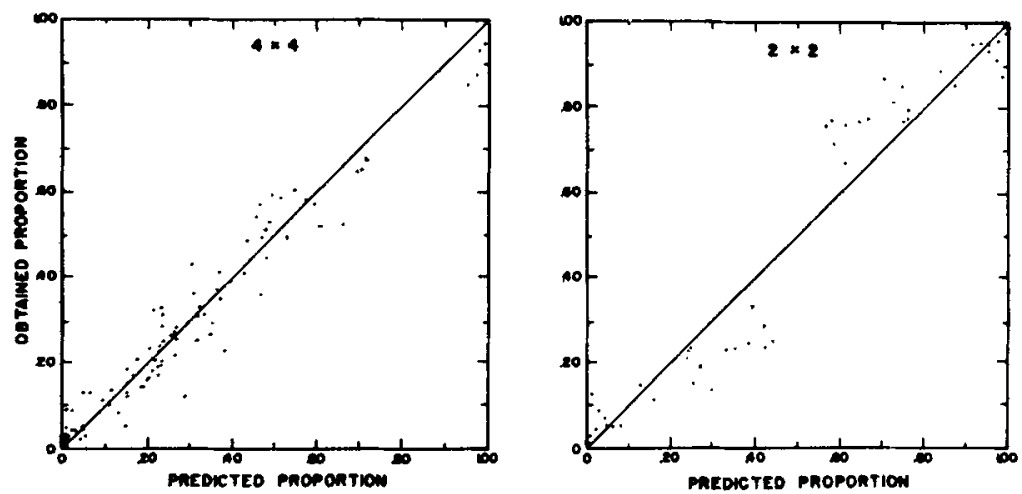

Fig. 3. Predicted and obtained response proportions of the individual 4 by 4 and 2 by 2 entries in Series $A$ of Experiment 1: Visual Area.

.026 in Series $D$ to .042 in Series C, with the other series taking intermediate values. The percentage of differences which exceeded .10 was small in all series. Thus, the small difference values lend support to the results shown in Flg. 3; the CRR makes rather good predictions of the 4 by 4 proportions. Furthermore, the small value of the algebraic mean in each series suggests that the systematic trend in the predictedobtained differences is moderate. For the 2 by 2 matrices, the difference measures were somewhat larger, indicating that the CRR predictions were less accurate. The systematic differences among the 2 by 2 proportions were particularly evident. As was the case in the lifted weights experiments, the most serious failures of the CRR occurred in matrices containing adjacent stimuli and responses. Although most apparent in the 2 by 2 matrices, this effect was also present in the 4 by 4 data.

Further evaluation of the CRR is provided by a comparison of the first and second halves of each series. In every series the mean absolute difference and the percentage of differences exceeding .10 were greatest in the second half of the rank ordered matrices. Since the mean proportion correct was always lowest in the second half matrices, the CRR predictions are apparently greatly dependent upon task performance; the difference measures increase with decreases in the mean proportion correct responses. A similar result was obtained in the lifted weights experiments.

Spacing-range Effects The effect of the spacing-range variable is summarized in Tables 3 and 4. Except for Series $C$, the mean absolute difference and the percentage of differences exceeding .10 in the 4 by 4 data of Table 3 became smaller with an increase in the ensemble range. The sign of the algebraic mean shifted from negative to positive, indicating that the CRR overestimates the response proportions in the narrowly spaced ensembles (Series A and B) and underestimates in the widely spaced ensembles (Series $C$ and D). Although not as definite, the same trends were present in the 2 by 2 data.

Table 4 presents a comparison of the derived and observed confusabllity scores (wrong responses) for selected pairs of stimuli. The first column represents the absolute distance (see Table 2) between the two members of the stimulus pair under consideration. The second column locates the stimulus pair in Table 2. The next four columns present, when available, the derived confusability obtained from the 8 by 8 matrix and the observed confusability determined from the 2 by 2 matrix. All entries in a given row represent the same stimulus pair. To be noted first is the influence of the "label" assigned in the 2 by 2 tests upon the observed confusability of a given pair (compare the entries within parentheses across a given line in Table 4). It is apparent that the observed confusabilities of certain pairs (e.g., those with a relative spacing of $0-6,1-4$, and $0-3$ ) tend to depend upon the labels assigned to the circles. However, since other pairs (e.g., $0-12,0-8$, and $0-2$ ) fail to show this dependency, a systematic relationship between labels and observed confusability is doubtful.

The most important point is that the derived confusabilities become larger as the range of the 8 by 8 matrix increases, $1 . e .$, the entries without parentheses increase across a given row in Table 4. Furthermore, the amount of change in derived confusability tends to become larger with decreases in the spacing of a pair. The change from Series $A$ to $D$ is greatest when the absolute spacing is 2,3 , or 4 units and least when the spacing is 6,8 , or 12 units. Table 4 also shows that both derived and observed confusabilities increase systematically with decreases in the spacing (examine the entries in each column of Table 4).

Practice Effects. The 16 practice trials with the 8 by 8 matrix of each series were grouped in blocks of four and then used to predict the proportions of the 4 by 4 and 2 by 2 matrices employed in the experimental trials. Thus, four sets of predictions were obtained for each series. All the 4 by 4 and 2 by 2 difference measures ${ }^{3}$ in each series declined systematically with practice on the 8 by 8 matrix, thus indicating that $\mathrm{CRR}$ predictions improve with practice on the task.

A possible limitation is the manner in which the practice variable was manipulated. Since the 4 by 4 and 2 by 2 proportions were predicted from each of 
the four blocks of practice trials, the predictions may have been confounded by the fact that all Ss were given the 16 practice trials before the 4 by 4 and 2 by 2 data were collected. Through the mechanism of transfer, practice on the 8 by 8 matrix may have greatly enhanced $\mathrm{Ss}^{2}$ performance on the 4 by 4 and 2 by 2 matrices, and thereby have produced inflated difference scores. To test the confounding hypothesis, 17 additional Ss were given 4,8 , or 12 trials on the 8 by 8 matrix (circles of Series A) before the 4 by 4 and 2 by 2 tests were conducted. The results ${ }^{3}$ showed

Table 3.

Summary of Results of Single and Multidimensional Experiments

\begin{tabular}{|c|c|c|c|c|}
\hline Experiment & $\begin{array}{l}\text { Mean Prop. } \\
\text { Correct }\end{array}$ & $\begin{array}{l}\text { Mean } \\
\text { [Diff.] }\end{array}$ & $\begin{array}{c}\% \\
\text { Diffs. } \\
>.10\end{array}$ & $\begin{array}{c}\text { Alg. Mear } \\
\text { Diogono } \\
\text { Diff. }\end{array}$ \\
\hline \multicolumn{5}{|c|}{4 by 4} \\
\hline \multicolumn{5}{|l|}{ Auditory ${ }^{a}$} \\
\hline $\begin{array}{l}\text { Durotion } \\
\text { Inten sity }\end{array}$ & $\begin{array}{l}.746 \\
.831\end{array}$ & $\begin{array}{l}.028 \\
.025\end{array}$ & $\begin{array}{l}4.2 \\
2.8\end{array}$ & $\begin{array}{l}+.014 \\
+.013\end{array}$ \\
\hline \multicolumn{5}{|c|}{ Intensity Spocing } \\
\hline A & .529 & .042 & 6.2 & -.006 \\
\hline $\mathbf{B}$ & .629 & .041 & 9.4 & -.068 \\
\hline C & .748 & .025 & 1.6 & +.066 \\
\hline D & .852 & .034 & 12.5 & +.053 \\
\hline \multicolumn{5}{|l|}{ Visual } \\
\hline $\begin{array}{l}\text { Brightness } \\
\text { Areo Spocing }\end{array}$ & .871 & \multicolumn{2}{|c|}{ Areo Spocing } & +.037 \\
\hline A & .579 & .037 & 7.1 & -.005 \\
\hline B & .692 & .031 & 3.6 & -.010 \\
\hline C & .714 & .042 & 8.0 & -.001 \\
\hline D & .781 & .026 & 2.7 & +.015 \\
\hline \multicolumn{5}{|l|}{ Lifted Woights } \\
\hline $6 \mathrm{~g}$ & .551 & .048 & 11.4 & +.004 \\
\hline 89 & .617 & .039 & 6.2 & +.017 \\
\hline \multicolumn{5}{|c|}{ MultiD. Auditory ${ }^{a}$} \\
\hline Coarse spacing & 19. 908 & .020 & 0.5 & +.020 \\
\hline Fine spocing & .666 & .028 & 1.6 & +.002 \\
\hline Redundant Obj & is. . 947 & .018 & 0.6 & +.028 \\
\hline \multicolumn{5}{|c|}{2 by 2} \\
\hline \multicolumn{5}{|l|}{ Auditory ${ }^{a}$} \\
\hline Duration & .933 & .082 & 28.6 & +.052 \\
\hline Intensity & .971 & .043 & 21.4 & +.042 \\
\hline \multicolumn{5}{|c|}{ Intensity Spocing } \\
\hline A & .756 & .054 & 10.0 & -.029 \\
\hline B & .803 & .051 & 6.2 & -.030 \\
\hline $\mathrm{C}$ & .904 & .034 & 5.0 & +.022 \\
\hline$D$ & .939 & .088 & 50.0 & +.084 \\
\hline \multicolumn{5}{|l|}{ Visual } \\
\hline $\begin{array}{l}\text { Brightness } \\
\text { Areo Spocing }\end{array}$ & .976 & .035 & 17.9 & +.022 \\
\hline A & .865 & .062 & 32.1 & +.042 \\
\hline $\mathbf{B}$ & .889 & .034 & 7.1 & -.001 \\
\hline $\mathrm{C}$ & .930 & .039 & 17.9 & +.035 \\
\hline $\mathrm{D}$ & .945 & .037 & 74.3 & +.032 \\
\hline \multicolumn{5}{|l|}{ Lifted Weights } \\
\hline 68 & .787 & .063 & 25.0 & +.003 \\
\hline $8 \mathrm{~g}$ & .868 & .084 & 21.4 & +.044 \\
\hline \multicolumn{5}{|c|}{ MultiD. Auditory ${ }^{a}$} \\
\hline Coorse spocing & g. .986 & .023 & 0.0 & +.018 \\
\hline Fine spacing & .846 & .038 & 0.0 & -.004 \\
\hline
\end{tabular}

a From Hodge and Pollack (1962)
Table 4. Obtained (in parentheses) and Predicted Confusability Scores for Selected Stimulus Pairs in Experiment 1

\begin{tabular}{|c|c|c|c|c|c|}
\hline $\begin{array}{l}\text { Absolute } \\
\text { Stimulus Spacing }\end{array}$ & $\begin{array}{l}\text { Relative } \\
\text { timulus Spacing }\end{array}$ & A & Seri & $C$ & D \\
\hline 12 & $0-12$ & & $\begin{array}{c}.010 \\
(.000) \\
1,7\end{array}$ & $\begin{array}{c}.010 \\
(.012) \\
1,5\end{array}$ & $\begin{array}{c}.013 \\
(.010) \\
1,4\end{array}$ \\
\hline \multirow[t]{2}{*}{8} & $0-8$ & & $\begin{array}{r}.008 \\
(.010) \\
1,5\end{array}$ & & $\begin{array}{c}.016 \\
(.006) \\
1.3\end{array}$ \\
\hline & $4-12$ & & $\begin{array}{r}.014 \\
3,7\end{array}$ & & $\begin{array}{l}.042 \\
2,4\end{array}$ \\
\hline \multirow[t]{2}{*}{6} & $0-6$ & $\begin{array}{c}.008 \\
(.009) \\
1,7\end{array}$ & $\begin{array}{c}.013 \\
(.032) \\
1,4\end{array}$ & $\begin{array}{c}.040 \\
(.036) \\
1,3\end{array}$ & \\
\hline & $6-12$ & & $\begin{array}{r}.042 \\
4,7\end{array}$ & $\begin{array}{r}.107 \\
3,5\end{array}$ & \\
\hline \multirow[t]{4}{*}{4} & $0-4$ & $\begin{array}{c}.023 \\
(.105) \\
1,5\end{array}$ & $\begin{array}{c}.052 \\
(.175) \\
1,3\end{array}$ & & $\begin{array}{c}.188 \\
(.064) \\
1,2\end{array}$ \\
\hline & $2-6$ & $\begin{array}{l}.045 \\
3,7\end{array}$ & $\begin{array}{r}.114 \\
2,4\end{array}$ & & \\
\hline & $4-8$ & & $\begin{array}{l}.120 \\
3,5\end{array}$ & & $\begin{array}{r}.196 \\
2,3\end{array}$ \\
\hline & $8-12$ & & $\begin{array}{c}.136 \\
(.110) \\
5,7\end{array}$ & & $\begin{array}{r}.222 \\
3,4\end{array}$ \\
\hline \multirow[t]{2}{*}{3} & $0-3$ & $\begin{array}{c}.069 \\
(.054) \\
1.4\end{array}$ & & $\begin{array}{c}.201 \\
(.112) \\
1,2\end{array}$ & \\
\hline & $3-6$ & $\begin{array}{l}.051 \\
4,7\end{array}$ & & $\begin{array}{l}.391 \\
2,3\end{array}$ & \\
\hline \multirow[t]{4}{*}{2} & 0.2 & $\begin{array}{c}.193 \\
(.150) \\
1,3\end{array}$ & $\begin{array}{c}.247 \\
(.148) \\
1,2\end{array}$ & & \\
\hline & $2-4$ & $\begin{array}{l}.218 \\
3,5\end{array}$ & $\begin{array}{c}.301 \\
2,3\end{array}$ & & \\
\hline & $4-6$ & $\begin{array}{c}.259 \\
(.197) \\
5,7\end{array}$ & $\begin{array}{l}.319 \\
3,4\end{array}$ & & \\
\hline & $6-8$ & & $\begin{array}{c}.314 \\
(.249) \\
5,6\end{array}$ & & \\
\hline
\end{tabular}

Note: The pairs of numerals, derived from Table 2 , represent pairs of stimuli and responses.

a 1.55 sq. in. units

that in every case CRR predictions improved with practice on the 8 by 8 matrix.

\section{EXPERIMENT 2: VISUAL BAIGHTNESS}

\section{Subjects}

The Ss were 12 students at the University of Georgia who were required to serve $1 \mathrm{~h}$ a day for 11 consecutive days, excluding weekends. The Ss were run in groups of six. 


\section{Stimulus Material and Apparafus}

The stimulus objects consisted of eight circles which varied in brightness. The eight steps of brightness were obtained by use of the Munsell neutral tint papers, ranging from $\mathrm{N} 5.5 /$ to $\mathrm{N} 9.0 /$ in half step values. With Stimulus 1 of Experiment 1 (Table 2) as a background, each Munsell paper was photographed and mounted in a 2 by 2 slide. The apparatus was identical to that of Experiment 1.

\section{Design and Procedure}

The design and procedure were similar to that of Experiment 1 except that fewer practice trials were given. After preliminary training had been completed, Ss were given 12 trials of practice on the 8 by 8 matrix and then the 32 experimental sequences of Experiment 1. With 12 Ss judging the stimuli in each sequence, a total of 576 responses was obtained for each stimulus in each ensemble.

\section{Results}

A summary of the results ${ }^{3}$ is presented in Table 3. The small values of the various difference measures indicate that the CRR makes good predictions of the 4 by 4 and 2 by 2 response proportions. The results also showed that the CRR predictions became progressively better with practice on the 8 by 8 matrix. An unexpected finding was that only in the 2 by 2 data were the predictions in the second half of the rank ordered experimental matrices poorer than the predictions in the first half. No explanation of the reversal in the 4 by 4 data can be offered.

\section{DISCUSSION}

To facilitate an evaluation of the CRR, the difference measures of the present experiments and those of the auditory studies (Hodge \& Pollack, 1962) have been collected together in Table 3. Inspection of the 4 by 4 measures indicates that the CRR predicts equally well the response proportions for the auditory and visual stimulus ensembles, and somewhat more poorly for the lifted weights experiments. The small values of the difference measures suggest that the 4 by 4 predictions are reasonably good, but, when compared with those for the multidimensional auditory ensembles, the predictions for the single dimensional stimuli are clearly less impressive, particularly in terms of the percentage of differences greater than .10. Turning to the 2 by 2 data, there is again little difference in the CRR predictions for the various stimulus dimensions. All the difference measures, and especially the percentage of differences greater than .10 , indicate that CRR predictions for the 2 by 2 matrices are poorer than those for the 4 by 4 data. And again, predictions for single dimensional stimuli are less accurate than those for multidimensional ensembles.
Taken as a whole, the predictions are good enough to make the CRR a useful tool in designing practical stimulus displays and response systems (cf., Engstrand \& Moeller, 1962). As a model of choice behavior, however, the rule as presently formulated is somewhat unsatisfactory. The results of the present experiments and those of Hodge and Pollack demonstrate that the CRR has difficulty predicting the response proportions of single dimensional ensembles, especially when the 2 by 2 matrices involve variations in the spacing-range conditions and practice on the task. While an attempt might be made to attribute the difficulties to defects in the experimental procedures, the similarity of the results of the various experiments, each of which differed somewhat in procedure, argues against such an analysis.

A more likely explanation is that single dimensional S-R matrices, in contrast to the multidimensional case, are subject to the strong differential effects of stimulus and response confusion (Clarke, personal communication, 1960; Hodge \& Pollack, 1962; Luce, 1959, 1963). Stimulus confusion reflects $S$ 's inability to discriminate perfectly among the objects of a stimulus ensemble while response confusion represents S's failure to use a set of response labels in a consistent fashion. In single dimensional identification tasks, differential stimulus confusion occurs whenever $\mathrm{S}$ does not perceive the stimuli as equally spaced on an ordered scale. As a consequence, the stimuli are not equally confusable, and therefore some of the stimulus objects "produce" more correct responses than others. With numerals as response labels (well practiced and familiar to adult Ss), discrimination among the responses is not a problem. Response confusion is the result of response preferences which $S$ expresses in varying degrees depending upon the amount of stimulus confusion present in a given situation. Support for this view is provided by Tune (1964), who has summarized considerable evidence which shows that response preferences become more pronounced with increases in the difficulty of stimulus discrimination. In tasks employing multidimensional stimuli, stimulus and response confusion are undoubtedly present, but presumably the relevant stimulus variables do not engender differential amounts of the two types of confusion. Hence, with stimulus and response confusion approximately equal for each stimulus and response, the CRR makes excellent predictions.

The effects of stimulus and response confusion in single dimensional tasks are seen most clearly in the spacing-range results of the visual area experiment. The fact that the derived confusability (obtained from an 8 by 8 matrix) for a given stimulus pair became larger with increases in the ensemble range (Series $A$ to $D$ in Table 4) suggests the presence of response confusion. Since a given stimulus pair was identical in all ensemble ranges, stimulus confusion should 
have remained constant. With some exceptions, e.g., pairs with small absolute spacing, the relative invariance of the observed confusability (obtained from a 2 by 2 matrix) of a given stimulus pair in Table 4 supports this supposition. A similar result was obtained by Hodge and Pollack (1962) in an auditory experiment. Unexplained, however, is why response confusion became larger with increases in ensemble range. Response confusion should have become less with the improved stimulus discrimination presumably accompanying the increases in ensemble range. A possible reason is that the amount of stimulus confusion systematically declined in the 8 by 8 matrices, thus permitting fuller expression of a weak but fairly constant response confusion. 4 Although stimulus confusion for a given pair was highly similar in the various 2 by 2 matrices, it may have undergone systematic changes in the 8 by 8 matrices.

More striking changes in the two types of confusion occur with changes in the absolute stimulus spacing. The column entries of Table 4 show regular increases in the observed and derived confusabilities with a reduction in stimulus spacing. Thus, while the derived confusability scores are primarily indicants of response confusion at large stimulus spacings, the same scores seem to reflect both stimulus and response confusion at smaller stimulus spacings. As would be expected, with decreases in the stimulus spacing the observed confusability scores, as measures of stimulus confusion, also become larger. Not surprisingly, these changes in the two confusability scores are most evident in the narrow ensemble ranges.

In evaluating the auditory experiments (Hodge \& Pollack, 1962), It was suggested that a positive algebraic difference score indicated response confusion and a negative score stimulus confusion. An examination of the algebraic means of the visual area experiment in Table 3 reveals that in general the means of the narrow series are negative in sign while those of the wide series are positive. These results are consistent with the earlier statement that response confusion is most evident in the wide ensemble ranges. The negative value of the means in the narrow series does not imply the absence of response confusion, but only that stimulus confusion is strong, and that it tends to overwhelm and oppose the response preferences of $S$. The small magnitude of the negative means suggests that the two types of confusion are approximately equal in strength. Further support of this interpretation is provided by the fact that the algebraic means obtained in the $8 \mathrm{~g}$ lifted welghts study are more positive than those of the $6 \mathrm{~g}$ experiment. The wider spacing of the $8 \mathrm{~g}$ steps reduced stimulus confusion and thus permitted a freer expression of response confusion. Similar results were obtained in the auditory spacing experiment (Table 3).

To state that stimulus and response confusion are of equal strength implies that the responses elicited by differential stimulus confusion tend to be counteracted by S's preexperimental response preferences. It is possible to imagine, however, situations in which stimulus confusion is so strong that essentially only random responses are occasioned by the task stimuli. In effect, rather than being differential, stimulus confusion is uniform for all the stimuli. An approximation to these conditions seems to describe the practice effects observed in the present experiments. At the outset of practice, the stimuli, especially in the 8 by 8 matrices, are highly confused by $S$ and he finds it easier to ignore the stimuli and rely on his response preferences to deal with the task. As the stimuli become more discriminable, he is able to use the stimulus information more often in making his responses and depends less on his response preferences. Concomitant with the reduction in stimulus and response confusion is an improvement in the accuracy of the CRR predictions and in performance of the task.

An unexpected result of the practice effects is that, as indexed by the CRR predictions, considerable practice is required to master a seemingly simple task. The $S$ appears to require an inordinate number of trials before he is able to use the stimulus information in a reliable fashion and not depend on his response preferences. If such is the case, some of the previous work with the absolute judgment task, e.g., the channel capacity experiments, may be seriously confounded by practice effects. Whether information measures are sensitive to the effects of stimulus and response confusion, as described in the present report, is not clear. However, "An informational analysis of [the auditory spacing-range experiment] indicated that the amount of information achieved with each stimulus series (relative to the maximum possible transmitted information) is independent of both the spacing within each series and the number of stimulus objects. The amount of transmitted information seems to be determined only by the range subtended by the stimulus series" (Hodge \& Pollack, 1962, p. 135).

The strong dependence on response preferences also probably explains the large positive algebraic means obtained for the second half of most of the 4 by 4 and 2 by 2 matrices. These means are based on stimulus ensembles in which the Interstimulus spacing is small. With the consequent high stimulus confusion, response confusion is strong, task performance is poor, and the CRR difference measures rather large. A similar explanation also accounts for the finding of the interstimulus analysis in the $8 \mathrm{~g}$ lifted weights experiment that the derived confusability scores are higher than the observed scores only when the stimulus objects are adjacent or nearly adjacent.

In conclusion, the present experiments demonstrate that: (a) CRR predictions are somewhat better for multidimensional than for unidimensional stimuli because of the absence of large differential amounts of 
stimulus and response confusion in multidimensional situations; (b) the CRR is sensitive to the effects of practice and stimulus spacing-range variables; (c) there is little difference in CRR predictions for auditory, visual, and kinesthetic stimulus dimensions; and (d) the operation of response biases make testing of the CRR with single dimensional stimuli very difficult. More satisfactory tests of the CRR will be possible only when response biases can either be controlled experimentally or their influence negated theoretically by adding a bias parameter to the model. Experimental control might be achieved by the use of equidiscriminable stimuli (Alluisi \& Sidorsky, 1958; Garner, 1952). Such stimuli would presumably minimize stimulus confusion, and hence keep response confusion at a low value, A bias parameter has been proposed by Luce (1963) for his choice theory, but a test of its usefulness is beyond the scope of the present report.

\section{References}

Altuisi, E. A., \& Sidorsky, R. C. The empirical validity of equal discriminability scaling. J. exp. Psychol., 1958, 55, 86-95. Anderson, C. D. The constant-ratio rule as a predictor of confusions among various stimuli of brief exposure duration. Tech. Note, AFCRC-TN-58-60, Hearing and Communication Laboratory, Indiana University, 1959.

Athinson, R. C., Bower, G. H., \& Crothers, E. J. An introduction to mathematical learning theory. New York: Wiley, 1965.

Curterette, E. C., \& Wyman, M. J. Confusion matrices in speech communication. Paper read at Psychonomic Society, New York, August, 1961.

Clarke, F. R. Constant-ratio rule for confusion matrices in speech communication. J. Acoust. Soc, Amer., 1957, 29, 715-720.

Clarke, F. R. Proportion of correct responses as a function of the number of stimulus-response alternatives. J. Acoust. Soc. Amer., $1959,31,835$.
Clarke, F. R., \& Anderson, C. D. Further test of the constant-ratio rule in speech communication. J. Acoust. Soc. Amer., 1957, 29. 1318-1320.

Egan, J. P. Monitoring task in speech communication. J. Acoust. Soc. Amer., 1957, 29, 482-489.

Engstrand, R. D., \& Moeller, G. The relative legibility of ten simple geometric figures. Amer. Psychologist, 1962, 17, 386.

Gamer, W. R. An equal discriminability scale for loudness judgments. J. exp. Psychol., 1952, 49, 232-238.

Hodge, M. H., \& Pollack, I. Confusion matrix analysis of single and multidimensional auditory displays. J. exp. Psychol., 1962. $63,129-142$.

Luce, R. D. Individual choice behavior. New York: Wiley, 1959. Luce, R. D. Detection and recognition. In R. D. Luce, R. R. Bush, \& E. Galanter (Eds.), Handbook of mathematical psychology. Vol. I. New York: Wiley, 1963. Pp. 103-189.

Pollack, I., \& Decker, L. Consonant confusions and the constant ratio rule. Lang. Speech, 1960, 3, 1-6.

Tune, G. S. Response preferences: A review of some relevant literature. Psychol. Bull., 1964, 61, 286-302.

\section{Notes}

1. The author is grateful to Morris J. Crawford, Mary Piercy, Roger K. Thomas, and Karen Buschow for their assistance in data collection and analysis, and to James C. Fortson for preparation of computer programs. Valuable criticism of the report was provided by Irwin Pollack and Earl A. Ailuisi. The research was supported by Contract No. AF 19(604)-7299 between the USAF Electronic Systems Division, Bedford, Massachusetts and the University of Georgia.

2. F. R. Clarke, personal communication, 1960.

3. Tables, similar to Table 1 and which summarize the data of all the visual experiments, have been deposited in the office of this Journal. Copies are available free upon request. A portion of this information is presented in Table 3 .

4. This minimal amount of response confusion may simply be the "unexplained" random variability often observed in psychological investigations, and it may be different from the response process described in the preceding paragraph.

(Accepted for publication May 24, 1967.) 